\title{
Sociedade, política e natureza. Conhecimento para qual sustentabilidade? ${ }^{1}$
}

\author{
Enrique Leff
}

Doutor em Economia do Desenvolvimento pela Universidade de Sorbonne, França. Professor Titular de Ecologia Política e Políticas Ambientais da Universidade Nacional Autônoma do México. Coordenador de 1986 a 2008 da Rede de Formação Ambiental para a América Latina e o Caribe, do Programa das Nações Unidas para o Meio Ambiente.

\section{INTRODUÇÃO}

Para mim é um momento muito especial estar aqui em Belém porque tenho uma espécie de saudade, não somente do já vivido, mas também do imaginado - o desejo de estar nesse lugar. E grande expectativa e alegria de encontrar velhos e queridíssimos amigos e amigas, amizades que foram construídas por estarmos envolvidos há muito tempo no debate sobre a questão ambiental. Essa convocatória é também especial por ser um convite honroso justamente vindo do Brasil. Como falou José Augusto Pádua, o Brasil é um lugar, no sentido de território, e cultura, com o qual talvez eu tenha um diálogo mais profundo. Isso não é porque aqui sou mais lido, mas porque aqui encontro uma sensibilidade muito especial pela questão ambiental. Não somente uma sensibilidade superficial para as questões de conservação da natureza, mas uma reflexão maior sobre as motivações que nos levam a querer pensar profundamente a direcionar nossas ações no mundo, e ir ao encontro do que falamos agora sobre sustentabilidade. Não só sustentabilidade ecológica, ambiental, mas sustentabilidade da vida.

\footnotetext{
Conferência inédita de abertura do VI Encontro Nacional da Associação Nacional de Pós-Graduação e Pesquisa em Ambiente e Sociedade (ANPPAS), em Belém, Pará, 2012.
} 
$\mathrm{E}$ por isso começo agradecendo sinceramente o convite para estar nesse "claustro", que não é nada claustrofóbico, mas um claustro aberto ao pensamento. Pensei muito sobre qual a temática que poderia trazer aqui para falar com vocês. Qual é a nova provocação? Qual a questão fundamental para falar à academia socioambiental do Brasil, a que considero mais apropriada neste mundo para essas conversações críticas? É falar da questão do conhecimento, porque a matéria que nos traz aqui não é somente a sensibilidade em geral sobre o ambiente. Mas é a tarefa fundamental e compromisso como professor, pesquisador ou aluno, de produzir uma reflexão seminal sobre o conhecimento. $\mathrm{O}$ conhecimento sobre o ambiente. Quando estamos entendendo o conhecimento com uma perspectiva de sustentabilidade, temos que nos perguntar: qual conhecimento? E a pergunta não vai se encerra na mera preocupação interdisciplinar, e sim uma consciência de que nenhum paradigma sozinho consegue compreender toda a complexidade ambiental. Precisamos falar, abrir diálogos entre disciplinas para termos uma compreensão mais completa e, portanto, mais responsável.

Mas já proferi a palavra que poderá ser o eixo de minha fala esta noite com vocês. A palavra é responsabilidade. Sabemos que os poucos pensadores que temos no mundo de hoje, e que estão pensando profundamente, já falaram que o século XXI, o qual estamos apenas começando, deve ser o século da responsabilidade. Ou não será. Isso quer dizer que as crises geraram uma reflexão profunda quengos leva a interrogar qual é a condição deste mundo que habitamos. Por que este mundo, após todo o iluminismo da razão, está em uma crise de razão? Nós falamos de crise ambiental. Qual é essa condição que foi mal feita neste mundo, e que o iluminismo não conseguiu enxergar? Parece que nos esquecemos e não conseguimos enxergar, apesar de tanto conhecimento; e falamos que atualmente estamos na sociedade do conhecimento. Temos ignorado as condições fundamentais da vida neste mundo, e com isso quero dizer que nos esquecemos da natureza e também das ciências sociais. Pontualmente, esquecimento, não conhecimento e não responsabilidade com as condições fundamentais da vida neste planeta. Assim, ignoramos e esquecemos as condições ecológicas pelas quais foi possível a vida neste planeta, e as condições de se ser um estranho - o ser humano - que habita neste planeta e que o transformou em um planeta quase inabitável. Eu não quero falar de qualquer responsabilidade. Quero me interessa falar da responsabilidade que nós, pesquisadores, acadêmicos, pensadores, intelectuais, estudiosos temos sobre essa questão atualmente no mundo. É uma responsabilidade que me leva à critica do conhecimento. E isto é uma questão que vai além da preocupação de identificar as causas e os canais de 
interdisciplinaridade. Estou levantando a "questão" do conhecimento que não conhece; que não sabe dessas condições fundamentais da vida.

Eu estava relendo um livro que li há vários anos, de um pensador que expôs as causas da desconstrução da pós-modernidade, e alguns de vocês já sabem que estou falando do grande Jacques Derrida. Estou me referindo a falou numa palestra similar a esta, uma conferência especial que fez em 1998 na Universidade de Stanford, na Califórnia (EUA). Nessa conferência Derrida chamou a atenção sobre uma "universidade sem condição" (l'université sans condition), sem condicionamentos. E ele falou a um público universitário, como faço hoje também me dirigindo a um público universitário, sobre a questão de abrir a cabeça para não ficar condicionado aos constrangimentos da razão, dos conhecimentos, e se permitir abrir para o que chamamos de "possível" neste mundo. E quando nós falamos de sustentabilidade, falamos desse possível - o possível para a sustentabilidade.

Então, qual é a relação importante no que diz respeito ao conhecimento para abrir os caminhos à sustentabilidade? Derrida aborda a questão a partir do debate do seu conceito fundamental da "diferença". Ele fala da diferença entre os saberes performativos e os saberes constatativos, sobre a crença de alguns pesquisadores que tratam os chamados conhecimentos constatativos como fáticos, e os saberes que associam às ciências humanas, às ciências sociais, que fazem um conhecimento mais literário, mais de narrativas, mais imaginativo, menos constatativo. Seja ou não verdade, todas as ciências, mesmo as ciências sociais, apropriaram-se do modelo de cientificidade das ciências naturais; e então estamos falando de um conhecimento performativo, quero dizer que é mais que um conhecimento - é uma atitude discursiva e imaginativa que precisa da imaginação para conseguir o que se afirma discursivamente.

Comecei explicando esse tema porque estava com essa mesma preocupação: como abrir, deslacrar os conhecimentos que estão nestas universidades, nestas academias, nestas ciências? Estes pensamentos que, deixe-me dizer assim, vão colonizando o mundo. E hoje, o que está tão em voga na América Latina é o pensamento descolonizador. Então vamos descolonizar o eurocentrismo que veio nos conquistar, colonizar os nossos modos de pensar, nossos modos de agir, nossos modos de produzir, nossas relações com a natureza. É preciso não só pensar a colonização que foi trazida pelos portugueses, pelos espanhóis, pelos franceses ou ingleses, atualmente por toda a globalização, mas pensar mais atrás na história. Quando falamos de desconstrução dos paradigmas, como foi possível construir um mundo com o nosso modo de produção que é insustentável? Não o modo de produção capitalista que é insustentável, mas o mundo do pensamento 
com raízes insustentáveis. Esta afirmação é muito mais forte, quer dizer, a culpa da insustentabilidade é sempre a culpa do capitalismo, porque vamos fazer uma revolução socialista, vamos sair desse modo capitalista, vamos nos emancipar do sistema colonial, vamos nos emancipar do capital, vamos inventar outros modos de produção.

Quando observamos uma visão desconstrutiva mais para trás na história, descobrimos que também todos esses eurocentrismos, todos esses modos de produção, todos esses capitalismos, toda essa racionalidade econômica não surgiram sozinhos, nasceram de uma raiz, de uma fonte de construção, de um momento que talvez tenha sido um acontecimento marcante na história da humanidade, mas que até hoje produz consequências.

Refiro-me a uma questão seminal que é a "violência do pensamento", pode-se dizer, desse pensamento ocidental que está enraizado, sobretudo, no pensamento grego, que foi o princípio do pensamento metafísico e de toda a história do conhecimento até agora; e suas consequências fazem parte da história do pensamento metafísico. Martin Heidegger, um dos grandes filósofos do século passado, faz uma profunda reflexão sobre a Metafísica, na sua obra "Ser e Tempo". Nessa obra ele confronta toda a história, não só do estudo da filosofia, mas da ciência produzida pela metafísica, pelo pensamento cartesiano, e pelo método cartesiano e, portanto, os princípios de produção do conhecimento objetivo das ciências. E ele apontou um erro histórico, fundacional, que é a dissociação, a disjuntiva que existe entre o ser no mundo - o pensar o mundo como ser, o ser do mundo - e o pensar o mundo como ente. E este pensamento do mundo, como um mundo que se pensa já com a presença dos entes, faz retornar todo o pensamento filosófico e científico para estudar os núcleos mais invisíveis que estruturam a matéria do mundo, o átomo, o gene, e o indivíduo na sociedade moderna. Tudo isso refaz uma maneira de olhar o mundo, e essa visão de mundo certamente é uma forma de construir o próprio mundo.

Heidegger tratou a metafísica - que é o plasma sobre o qual se constrói as ideias, as ciências - como produtora de uma certa violência sobre o mundo, uma metafísica da presença, uma metafísica que leva a olhar somente o que se faz presente. É posto, também, que Heidegger dizia que a ciência não pensa - no sentido filosófico -, na questão das causas metafísicas, das causas do pensamento; não pensa o futuro, mas o que está feito, os feitos, os fatos da realidade. É uma tentativa de reconstruir o mundo com uma ambição de objetividade, da prova, do que é erro.

Todos esses métodos que vêm da falsificação, da falseação weberiana, de uma verificação, que para os historiadores é onde toda a historiografia da ciência 
vai pousar a ideia de revolução científica, de construção de paradigmas mais abrangentes sobre a realidade, para que consigam compreender de forma muito mais ampla processos materiais e simbólicos, como fez Freud com a ideia - ou mesmo Lévi-Strauss - já que seus objetos de conhecimento não são de caráter material, bem como energético, mas são processos simbólicos do ser humano.

Entretanto, tudo convergiu para a situação atual do conhecimento - o grande momento na história do conhecimento das epistemes do mundo, como foi analisado por Michel Foucault, chegando ao momento da constituição formal das teorias dos sistemas, do estruturalismo, que talvez já estivesse mais aberto à ideia de sistemas, mas sempre com a ideia de totalidade sistêmica, de conseguir tocar, de apreender o mundo através da multiplicidade de determinações. Vocês sabem que o pai desta corrente totalitária do pensamento científico metodológico foi Karl Marx, quando afirmou que "o concreto é concreto porque é a síntese das múltiplas determinações".

Então, como analisar as transições nesse momento fundacional? Considerando o momento anterior, de dissociação entre o ser e o ente, como o momento da emergência do humano, do simbólico na evolução do planeta vivo. Até mesmo o estruturalismo - ou o próprio Lévi-Strauss - dizia que não era questão da ciência pensar esse momento mais "natural"; de que a natureza foi aparentemente perdida somente porque emergiu o simbólico, a cultura, o ser humano. Mas, após esta dissociação entre cultura e natureza, para nós não tem sido possível reconectá-las no mundo. A partir dessa bifurcação, surgiu, então, a ideia de conhecimento que abordou o sentido da vida, e daí se construiu a história do conhecimento, do pensamento, o que certamente levou a formular os princípios da teoria de Descartes, da objetividade e subjetividade. A divisão entre a razão e a paixão. E nós ambientalistas, o que estamos pensando? Estamos pensando na necessidade de romper com a separação entre sociedade e natureza, sobretudo nesse momento fundacional desta interdisciplinaridade. Isto que estamos querendo agora transpor num nível holístico - de se re-encausar, rever o que foi dividido por meio do conhecimento.

Bem, vocês vão dizer, basta de tanta filosofia. Mas como nós incorporamos isso nos nossos paradigmas? E esses paradigmas, vocês bem sabem, são aqueles que desconhecem a natureza. Para a economia, a natureza é uma externalidade e quando procura internalizar essa externalidade o faz recodificando a natureza, não só no âmbito ecológico, como uma possível economia ecológica, mas em planos estritamente econômicos, assinalando preços de mercado, direitos de propriedade privada, intelectual, etc. Então, estamos observando esses processos, e tudo vai se tornando mais complexo. Atualmente estamos vivenciando a presença 
e a ausência dessa metafísica, onde o simbólico é ainda mais complexificado, mais pervertido, num momento em que as ciências tentam construir verdadeiras estratégias de poder no próprio saber. Nas apropriações do mundo por cada uma dessas disciplinas, por esses grandes paradigmas, encontramos muita resistência para incorporar verdadeiramente a incerteza, os não saberes, os saberes dos outros à imaginação sociológica e antropológica, aos imaginários das pessoas, das culturas. Contudo, nesse tipo de interdisciplinaridade nós ainda continuamos dentro de um mundo determinado metafisicamente.

Nós sabemos que o ambiente, com todo esse interesse pela sustentabilidade, já faz parte de alguns desses cenários, desses paradigmas nos quais buscamos conhecer objetivamente uma série de questões. Tentamos criar o risco, mesmo sabendo que há riscos por todas as incertezas, mas ainda procuramos intervir de maneira racional sobre o mundo. Porém, fica muito difícil assumir esses erros históricos do conhecimento, além da falta de conhecimento, de razão e de sensibilidade dos seres humanos, por termos construído uma modernidade insustentável. Como sair dessa situação? Basta estes exercícios desconstrutivos para então rever as teorias e saber como foram erguidos os núcleos da racionalidade que passaram do âmbito da ciência para se transformar em instituições, porque o problema do mundo não é somente o que temos que institucionalizar dentro da academia, mas também a racionalidade econômica que já foi racionalizada no mundo, como um modo de ser do mundo e um modo de ser neste mundo. E a grande pergunta diante da sustentabilidade é: será que a economia conseguirá gerar toda a complexidade, todos esses outros ordenamentos ontológicos à ecologia? Não só os ordenamentos biológicos da vida, mas da própria existência humana. Estamos em um caminho certeiro de sustentabilidade? E ainda arriscaria... Essa é uma grande afirmação, mas creio que todas as academias científicas, não as brasileiras, mas do mundo, estão envolvidas nesses paradigmas de conhecimentos objetivos. Não só a economia, mas a sociologia, todas as tecnologias, tudo está voltado para olhar com convicção e certa clareza, qual é a condição do mundo, da transgênese, da inovação da tecnologia sobre a própria vida.

Podemos criar novas disciplinas. A ecologia política possibilita abordar os conflitos distributivos, as disputas conceituais paradigmáticas, as invenções de sustentabilidade, para construir objetivamente uma sociologia empírica que se manifesta nos conflitos socioambientais. Como tanto defende a sociologia anglo-saxônica atualmente, vamos ver qual o fim desta perspectiva construtivista, de forma a verificar como questões intrinsecamente de risco são convertidas em casos a serem analisados sociologicamente. Veja, a sociologia ambiental que supostamente estaria preocupada por ressignificar natureza e sociedade, fica 
com todas essas resistências e busca reafirmar o sentido do saber sociológico ao analisar os seus interesses, os imaginários, os processos políticos, mesmo aqueles que fazem em um dado momento, uma situação de crise ecológica, e possa se converter numa questão que mobiliza a sociedade para um propósito de sustentabilidade, de controle de elementos tóxicos, etc.

Importantes nomes da sociologia atual - e eu falo de Anthony Giddens e Ulrich Beck -atuam ainda dentro de uma discursividade da incerteza, mas, similar às causas epistemológicas do risco, sem buscar compreender quais seriam as saídas encontradas pela humanidade frente a esses riscos. Afirmar uma crença na clarividência recuperada do sujeito, da individualização, como faz Ulrich Beck, é certamente uma irresponsabilidade científica e intelectual. Qual é a capacidade do indivíduo de agir neste mundo condicionado pela tecnoeconomia para mudar o mundo? Todos os indivíduos, todos nós, somos forçados a agir diante das grandes incertezas provocadas por este mundo colonizado, pela sua dependência econômica e tecnológica. Somos forçados a tomar decisões, a avaliar a nossa capacidade de reflexão, mas isso não significa que estamos abrindo nossas cabeças, usando a nossa racionalidade não colonizada para entender quais as diretrizes para a construção da sustentabilidade. É fácil dizer "outros mundos são possíveis". É lindo estarmos avançando também aqui no Brasil, como foi concebido nos Fóruns Sociais Mundiais, em Porto Alegre, por exemplo.

Estou convencido que outros mundos são possíveis, mas, para isso, precisamos fortemente desconstruir o sentido mais teórico dos paradigmas que têm colonizado a vida no planeta. Estamos também numa investigação estratégica e política para desconstruir e analisar a transição que não será uma tomada de poder de um líder para outro ou de um grupo social sobre os conhecimentos já estabelecidos no mundo. Trata-se de repensar o mundo, de estar aberto para repensar e construir de outra maneira - e aí que é muito interessante o que está ocorrendo no mundo, fora dos domínios das universidades. É a reivindicação dos saberes diversos, que não carecem de cientificidade para retomar a sua legitimação; dos saberes do viver bem, por exemplo, do pensamento dos povos Aimarás e Quéchuas, hoje muito populares; dos direitos culturais dos povos tradicionais, que estão emergindo para recuperar e reinventar suas identidades. E, como afirmam muitos desses protagonistas, notadamente no Equador, mas também em outras regiões, tantos povos falam nessas lutas, que são culturais, políticas e epistemológicas.

Só será possível reconstruir este mundo fazendo valer, legitimando e revalorizando os saberes tradicionais. É extremamente complexa a reinvenção dessas identidades, que se tornam visíveis nos conflitos socioambientais ocorrentes 
em todo o mundo. Quando falo em reinvenção de identidades, estou pensando claramente, por exemplo, na reinvenção da identidade dos seringueiros, daqueles que não eram nativos de uma localidade; talvez pelas lutas sindicais e históricas, foram se identificando com a natureza de onde retiravam os recursos para viver, de acordo com as potencialidades e os condicionamentos dessa natureza.

E nós devemos, sim, tentar resgatar a riqueza contida nesses saberes dos povos tradicionais, e podemos pensar que ainda não foram colonizados ou mantêm uma resistência em serem colonizados, na esperança de encontrar uma forma de resgatar os imaginários sociais da sustentabilidade - sendo uma questão ainda muito especulativa, pois até mesmo a antropologia não deu muita atenção para o resgate desses imaginários. Eu gosto muito da história ambiental, que é um dos espaços mais maravilhosos que têm sido criados nesta rede de pesquisa. Talvez também estejam muito preocupados em retomar a questão do envolvimento entre sociedade e natureza, e como ocorre essa dissociação para gerar muita destruição ecológica e escravismo, muitas questões são postas pelo esquecimento dessa relação, desta história, o que Nietzsche chamaria de uma "vontade de poder", que esqueceu o outro, os outros, as pessoas e a natureza.

Mas, pouco foi feito na antropologia para resgatar o que está nos imaginários sociais da sustentabilidade. Quando digo resgatar, estou afirmando que é uma pergunta que deva ser feita, para saber se ela está aí. E também me faço essa pergunta, se eu acredito que a sustentabilidade não pode ser o resultado disso que os sociólogos da modernidade - os "Guiddens" e os "Becks" falam de modernidade reflexiva. Ou seja, o que a modernidade mantém para se retroalimentar de racionalidades modernas, para sair da captura da racionalidade na modernidade. Isso que Marx Weber definiu como a "aura da racionalidade." E quando ele falava disso, referia-se à modernidade construída sobre este modelo de racionalidade. Toda a modernidade se converteu em um processo de racionalização, mesmo em termos freudianos - uma racionalidade que tem invadido a sociedade humana no mundo.

Então, a pergunta especulativa consiste em saber se o ser humano nasceu de uma condição de vida decorrente deste planeta. Temos que nos perguntar se em determinado momento, na constituição da sua cultura, ele assimilou profundamente as condições para viver neste planeta, para uma vida sustentável. Nós bem sabemos que a reprodução da vida humana pressupõe que o incesto pode ser universal. É possível verificar, por meio de estudos antropológicos, ecológicos e culturais, o tabu do incesto como uma "lei universal". Trata-se de que não foi produzido por Sófocles, nem por Freud, mas um saber inerente ao ser humano. Isso não significa que vai ser gerada uma consciência que não pode 
ser alterada e nem provocada, mas é um conhecimento ou um saber próprio da condição humana.

E a ideia consiste em saber se a entropia, como uma lei de natureza mais geral, que atua sobre os processos naturais do mundo, foi introjetada de alguma maneira por essas culturas. Se quando os Aimarás e os Quéchuas falavam de viver bem, com a ideia de harmonização com o cosmos, com os processos ecossistêmicos, com a natureza, com os membros da sua comunidade e de outras comunidades, se já existia uma noção da condição entrópica da vida. E, além disso, eles têm uma noção, do que podemos dizer, cientificamente, com base em Erwin Schrödinger, de que imersos nesse pensamento já científico sobre o comportamento do cosmos, do mundo, da vida, é possível falar de um princípio de megaentropia. Porque, deixe-me avançar, eu vejo o horizonte da sustentabilidade somente como um equilíbrio entre processos de degradação entrópica, que são gerados pelo crescimento econômico e tecnológico, e talvez, fora isso, como bem descreveu Georgescu-Roegen, sinteticamente, mas com grande clarividência, ao tratar da relação entre o processo econômico e a lei da entropia. O modo econômico está no mundo como forma de ser neste mundo, um processo que magnifica, que exacerba os processos entrópicos que se dão no universo e na terra, mas com uma grande diferença: não são processos naturais; são processos gerados pela economia, que se alimenta cada vez mais e de forma crescente da natureza, e que transforma a entropia, segundo a ciência.

Mas o que todos esqueceram, mesmo Georgescu-Roegen e todas as ciências até agora, eu diria, é que a vida existe porque existe um processo megaentrópico, que captura as energias solares para a transformação em energia verde, em matéria vegetal. Sem esse princípio não teríamos vida neste planeta. Ninguém pensou, exceto Schrödinger, que falou desses processos de fotossíntese como megaentropia. Nenhum dos cientistas contemporâneos mencionaram isso, nem mesmo os sociólogos ou os economistas, pois é um tabu pensar nesses termos; em construir uma sociedade megaentrópica e essa sociedade teria de ser construída sobre os princípios da vida, mas acabou se tornando uma racionalidade contranatural.

Então, volto à minha primeira questão, porque gostaria de receber realmente comentários críticos, e exatamente por isso que estou formulando aqui essas ideias. E não quero fazer disto um monólogo, pois vai contra a minha intenção de um diálogo de saberes. Pergunto, então: como poderemos converter esses processos políticos inovadores com vistas à descolonização do saber, para se pensar esses outros saberes? Como observá-los objetivamente para se produzir uma ciência de qualidade, uma ciência que a Capes e o CNPQ valorizarão para 
distribuir bolsas e para manter-nos como entes acadêmicos? Por que temos que ser homo economicus e entes acadêmicos? Nossa preocupação não é somente manter-nos como acadêmicos, mas como estamos incertos na problemática da sustentabilidade, temos a responsabilidade sobre o conhecimento no qual estamos construindo as nossas teorias, nossas metodologias, com as quais estamos pronunciando enunciados para as gerações futuras, estamos influenciando a cabeça dos jovens, as novas gerações. Até bem pouco tempo atrás a preocupação do cientista era produzir em seus alunos uma espécie de "alter ego", que os faziam continuar produzindo dentro do seu (nosso) paradigma, da sua metodologia. Talvez o aluno melhore alguma coisa na pesquisa do grupo, talvez seja possível até fazer uma revolução científica e ganhar um Prêmio Nobel. Talvez. Mas vai ficar sempre no âmbito de uma tradição científica, de uma corrente de pensamento teórico, contra a natureza das coisas e o planeta.

Como produzir uma boa ciência? Qual é a ética que faz com que uma pessoa se converta em um bom pesquisador? Eu provoco aqui a discussão de que só isso não vai conduzir à sustentabilidade; que não há uma reflexividade desse conhecimento, desse pensamento da presença, da objetividade das coisas. O mundo está muito colonizado, por isso, não basta apenas criticar a ausência dos fundamentos da sustentabilidade da economia. Sou consciente de que muitos de vocês estão envolvidos em processos com comunidades, e que também há uma ética de como fazer pesquisa participativa com essas comunidades, em respeitar as suas culturas, resgatar os seus saberes, fazer valer os seus direitos. A questão é: o quanto isto é suficiente? Talvez haja um certo fechamento da academia para esses processos, por mais que possamos entendê-la como lugar de fomento da interdisciplinaridade, da pesquisa participativa com ética, com respeito. Mas temos que ter uma responsabilidade para além disso, uma vigilância epistemológica.

Nós nos formamos nas ciências sem termos uma cadeira sobre a história epistemológica da ciência que produzimos. Poucos pesquisadores entram nessa dimensão, de saber de onde surgiu a economia, a sociologia que estamos fazendo, a origem da antropologia, como veio se constituindo o pensamento antropológico, sociológico e mesmo o matemático. Mas não somente este saber sobre as origens, o plasma sobre o qual nós construímos os nossos conhecimentos. Podemos assumir essa tentativa como uma desconstrução que vai além de saber como foram construídos os núcleos da racionalidade.

Como então podemos reconstruir um novo conhecimento? Como podemos construir aquilo que venho falando há algum tempo, uma nova racionalidade? Uma racionalidade ambiental? A mesma racionalidade ambiental, 
uma racionalidade reflexiva para reformular, moldar e reconstituir um pouco desta racionalidade que tem sido objeto da crítica a modernidade. A abertura para um paradigma da racionalidade ambiental. Uma convocatória para pensála - ou ainda repensá-la, voltar o pensamento, como dizia Heidegger sobre o já pensado, "para pensar o que está além do que pode já estar sendo pensado". Assumir um direito, uma responsabilidade com o conhecimento humano para abrir novos paradigmas, novas observações, novas formas de construção do mundo, a partir desse pensamento, desse conhecimento. E aí que a categoria de diálogos de saberes abre uma proposta política do ser no mundo. Não é um simples diálogo de saberes; é uma proposta de interdisciplinaridade que vai além, estende-se para a transdisciplinaridade, ou seja, para poder dialogar com outros saberes não científicos, não paradigmáticos, não objetivistas, não constatativos.

É um pensar a história por um encontro de diferentes formas de viver neste mundo, e romper com a ideia de um ser genérico para a morte, que foi pensada por Heidegger. Não pensar somente na unidade, a condição igualitária para todos os humanos, porque todos nós sabemos que vamos morrer algum dia, mas também pensar o ser existencial, o sentido de um ser constituído por diversos saberes. Os seres que atuam e interagem no mundo são constituídos de saberes, valores e culturas diferenciadas. Nesses saberes estão constituídos os seus imaginários, suas práxis sociais e a sua relação com a natureza. E isto constitui uma política da diferença, que vai além do pensamento pós-moderno, que normalmente se detém ao pensamento filosófico abstrato e se apropria do pensamento crítico para convertê-lo na política da diversidade, da diferença. Mas não somente a ontologia da diferença, mas uma política da alteridade, que ultrapassa este pensamento, o que encontramos em Emmanuel Levinas, na ideia de epifania do rosto, de uma ética que vai antes e além da ontologia - na crítica do próprio Levinas a Heidegger.

Não se trata somente de voltar o olhar sobre o ser do mundo, o ser das coisas, mas de ir em direção a uma ética fundamental, do olhar, do face a face entre os seres humanos, axioma que fundamenta a questão ética trazida da tradição hebraica, mas, neste caso, estamos esquecendo um pouco da relação com a natureza, em que estão os olhares entre os povos, que se relacionam de formas diversas. E, entre os quais estão introjetadas as identidades culturais as condições ecológicas e naturais da existência humana.

Vivemos em um mundo globalizado, "homogeneizado por uma cultura hegemônica", uma globalização tecnoeconômica, que domina o mundo e configura os modos de vida. A única forma de superar dominação não é somente pelo pensamento filosófico, mas incorporando esse pensamento à política. E, 
com base nesse princípio, formular políticas e instituir direitos que permitam um diálogo entre seres x saberes, não somente um diálogo acadêmico ou entre disciplinas, mas um encontro muitas vezes conflitante entre distintas visões de mundo, em diferentes culturas. E deste encontro deve surgir uma fertilidade do pensamento social, para repensar a própria condição humana em situações diferenciadas e territórios distintos. E a partir desse diálogo construir um cenário de tolerância, de abertura, de aprendizagem e, de diferentes épocas. Teria que dizer que essa diferença de idade não pode ser reabsorvida em uma mesma época, por uma unidade. Quer dizer, reconhecer este mundo de diferenças, de outras idades absolutas, e reconciliá-las em uma unidade. E isso implica uma reconvenção do mundo que está construído sobre a ideia do uno, do universal, do geral, do eterno, da ideia de unificação do mundo.

E, verdadeiramente, nós falamos muito no chamado âmbito socioambiental, da diversidade de direitos, passando por uma política desta natureza. Sei que estou falando de coisas que eu não tenho a receita. Não tenho. Mas essas ideias podem ser confrontadas com muitas outras, de pensadores, de concepções que buscam a sustentabilidade da vida para prolongar a existência da sociedade. Nós procuramos um reencontro com a vida, com a natureza. Ao concluir, reafirmo a grande responsabilidade que nós acadêmicos temos com o conhecimento, e ele deve nos provocar para a ampliação dos diálogos de pensamentos e a construção de uma nova sociabilidade. Muito obrigado. 